Rev. Bras. Saúde Prod. Anim., Salvador, v.13, n.2, p.318-329 abr./jun., 2012 http://www.rbspa.ufba.br ISSN 15199940

\title{
Cultivares e épocas de semeadura de milheto para produção de forragem ${ }^{1}$
}

\author{
Cultivars and sowing dates of pearl millet for forage production
}

\author{
QUEIROZ, Domingos Sávio²; SANTANA, Sabrina Saraiva³ ${ }^{3}$ MURÇA, Tássio \\ Bonomo $^{3}$; SILVA, Edilane Aparecida ${ }^{4}$; VIANA, Maria Celuta Machado ${ }^{5}$; RUAS, José \\ Reinaldo Mendes ${ }^{6}$
}

\footnotetext{
${ }^{1}$ Financiado pela FAPEMIG.

${ }^{2}$ Empresa de Pesquisa Agropecuária de Minas Gerais, Unidade Regional EPAMIG Zona da Mata, Viçosa, Minas Gerais, Brasil.

${ }^{3}$ Universidade Federal de Viçosa, Viçosa, Minas Gerais, Brasil.

${ }^{4}$ Empresa de Pesquisa Agropecuária de Minas Gerais, Unidade Regional EPAMIG Triângulo e Alto Paranaíba, Uberaba, Minas Gerais, Brasil.

${ }^{5}$ Empresa de Pesquisa Agropecuária de Minas Gerais , Unidade Regional EPAMIG Centro-Oeste, Prudente de Morais, Minas Gerais, Brasil.

${ }^{6}$ Empresa de Pesquisa Agropecuária de Minas Gerais, Unidade Regional EPAMIG Norte de Minas, Nova Porteirinha, Minas Gerais, Brasil.

*Endereço para correspondência: dqueiroz@epamig.br
}

\section{RESUMO}

Com o objetivo de avaliar a produção e a composição química da forragem de milheto (Pennisetum glaucum (L.) R. Br.), plantado durante os períodos de transição chuva/seca e seca/chuva, sem irrigação, foi conduzido um experimento na EPAMIG de Leopoldina-MG, durante o período de fevereiro a dezembro de 2006. Os tratamentos foram arranjados num esquema fatorial $3 \times 5$, com as cultivares de milheto Comum, BN2 e BRS1501, plantadas nos meses de fevereiro, março, abril, agosto e setembro. Não houve diferença entre as cultivares na produção de massa de forragem seca, com média de $4.010 \mathrm{~kg} / \mathrm{ha}$. Houve diferenças entre as cultivares, somente, quanto aos teores de proteína bruta (PB) e digestibilidade in vitro da matéria seca (DIVMS). Os teores de PB, fibra em detergente neutro e digestibilidade in vitro da matéria seca variaram de 14,04 a 17,95\%, 48,78 a $57,27 \%$ e 61,37 a $72,68 \%$, respectivamente, de acordo com as cultivares e épocas de plantio. As diferenças entre as épocas de plantio foram significativas com a produção de massa de forragem seca de $3.941 ; 2.525 ; 4.316 ; 3.258$ e $6.010 \mathrm{~kg} / \mathrm{ha}$ para o plantio em fevereiro, março, abril, agosto e setembro, respectivamente. Como a composição química das cultivares variou aleatoriamente com as épocas de plantio, qualquer uma das cultivares pode ser utilizada. A semeadura em setembro proporciona as melhores respostas em produção sem comprometer a composição química.

Palavras-chave: composição química, pasto temporário, Pennisetum glaucum

\section{SUMMARY}

Aiming to evaluate the forage production and chemical composition of pearl millet (Pennisetum glaucum (L.) R. Br.) during rain/drought and drought/rain period transitions, without irrigation, this experiment was carried out at EPAMIG of Leopoldina-MG. Treatments were arranged as a $3 \times 5$ factorial: pearl millet cultivars: Comum, BN2 and BRS1501 and sowing dates (February, March, April, August and September). There was no differences among cultivars in dry forage mass production, with average of $4,010 \mathrm{~kg} / \mathrm{ha}$. There was difference among cultivars in crude protein (CP) and the in vitro dry matter digestibility (IVDMD). The $\mathrm{CP}$ values ranged from 14.04 to $17.95 \%$, while the neutral detergent fiber variation was from 48.78 to $57.27 \%$ and the IVDMD was from 61.37 to $72.68 \%$, according to the cultivars and sow time. There were differences among sow dates, with 
dry matter production of 3,$941 ; 2,525 ; 4,316$; 3,258 and $6,010 \mathrm{~kg} / \mathrm{ha}$ in the sowing dates of February, March, April, August and September, respectively. Anycultivar may be choosed, because the variations that were found in the chemical composition among cultivars according to sowing dates were variables. The production was better for sowing in September without changes in chemical composition of forage.

Keywords: chemical composition, Pennisetum glaucum, temporary pasture

\section{INTRODUÇÃO}

Reconhece-se que a estacionalidade de produção das forrageiras é um dos fatores que mais interferem na adoção de práticas corretas de manejo do pastejo, pelas oscilações que provoca na disponibilidade de forragem. A estacionalidade de produção das forrageiras torna obrigatória a adoção de práticas de conservação de forragem ou o cultivo de forrageiras aptas à colheita ou ao pastejo, durante $o$ período de entressafra, irrigadas ou não. A não adoção destas técnicas pelos produtores resulta em baixos índices de produtividade e na degradação dos pastos, que são submetidos ao super-pastejo, durante o período seco do ano. As estratégias de alimentação do rebanho no período seco do ano também podem exercer um grande impacto no custo de produção, a depender da alternativa utilizada.

O milheto é uma gramínea recomendada para cultivo no verão, de ciclo curto, crescimento rápido, com boa capacidade de rebrota e alto valor nutritivo, além de boa tolerância a estresses hídricos, o que permite seu cultivo em épocas de menor precipitação (GUIMARÃES JÚNIOR et al, 2009). Decorrente dessas características, tem sido amplamente usado em diversas modalidades de cultivo, como formador de palha para plantio direto (SPEHAR \& TRECENTI,
2011), forragem para pastejo direto (COSTA et al., 2011) ou ensilagem (GUIMARÃES JÚNIOR et al, 2009), além do plantio convencional para produção de grãos (COSTA et al., 2005). A utilização de milheto para pastejo pode ser uma alternativa para aumentar a disponibilidade de forragem nos meses de transição chuva/seca e seca/chuva, porque prolonga a estação de pastejo e reduz a demanda por alimentos armazenados, além de promover um descanso para a recuperação completa do pasto no início da estação chuvosa. Em sistemas de integração lavoura-pecuária, praticado em regiões tropicais, pode ser cultivado no outono/inverno para pastejo, durante o período seco, suspendendo-se o pastejo, no início do período chuvoso, para rebrota e acúmulo de massa para plantio direto.

$\mathrm{O}$ número de cultivares no mercado brasileiro e as informações sobre a utilização do milheto, para fins forrageiros, ainda são poucos em relação a cultivares de milho e de sorgo. Essa ausência demanda pesquisas com os cultivares disponíveis e as melhores alternativas de utilização. O objetivo com este trabalho foi avaliar a produção de forragem e a composição química de cultivares de milheto plantadas em várias épocas do ano como alternativa forrageira, durante os períodos de transição chuva/seca e seca/chuva, sem irrigação.

\section{MATERIAL E MÉTODOS}

O experimento foi conduzido na Fazenda Experimental de Leopoldina, da EPAMIG, a $21^{\circ} 28^{\prime} 49^{\prime \prime}$ de latitude sul, 42 43 '35" de longitude oeste e $235 \mathrm{~m}$ de altitude, durante o período de fevereiro a dezembro de 2006. O clima de Leopoldina é tropical úmido do tipo 
Aw, de acordo com a classificação de Köppen, com inverno seco e verão chuvoso (ANTUNES, 1986). A temperatura do mês mais frio é superior a $18^{\circ} \mathrm{C}$. Na Figura 1 são apresentados os dados de precipitação mensal obtidos na Fazenda Experimental de Leopoldina, durante a condução do experimento e a média histórica de 30 anos.

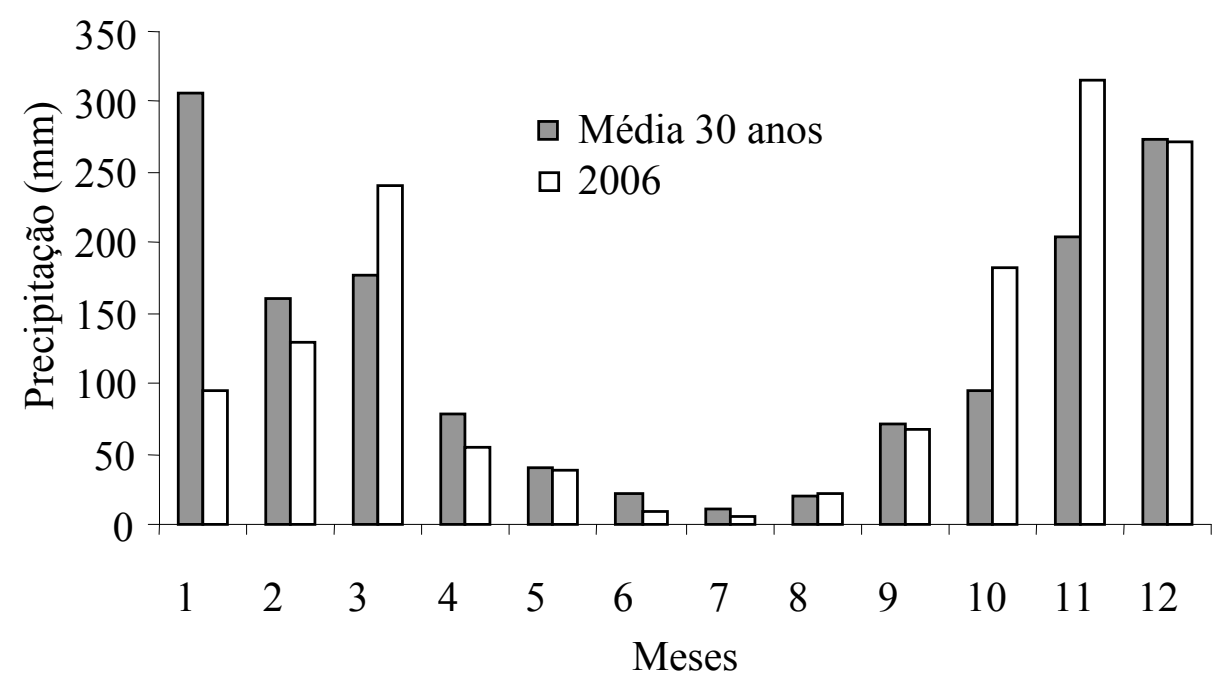

Figura 1. Precipitação mensal na Fazenda Experimental de Leopoldina durante a condução do experimento e média histórica de 30 $\operatorname{anos}(1974$ a 2003)

$\mathrm{O}$ experimento foi implantado num solo de meia-encosta, com aproximadamente $15 \%$ de declividade, classificado como argissolo vermelho-amarelo eutrófico (EMBRAPA, 2006), com as seguintes características químicas na camada de 0 a 20cm: $\mathrm{pH}$ em $\mathrm{H}_{2} \mathrm{O} ; 6,1 ; \mathrm{P}$ e K (Melich-1) 3,4 e $64 \mathrm{mg} / \mathrm{dm}^{3}$, respectivamente; Ca, $\mathrm{Mg}$ e $\mathrm{Al}(\mathrm{KCl} 1 \mathrm{~mol} / \mathrm{L}), 2,0 ; 0,7$ e $0 \mathrm{cmol}_{d} / \mathrm{dm}^{3}$, respectivamente; matéria orgânica, $3,2 \mathrm{dag} / \mathrm{kg}$, saturação por bases, $54 \%$ e CTC pH 7, $5,34 \mathrm{cmol}_{\mathrm{d}} / \mathrm{dm}^{3}$. Os teores de zinco, ferro, manganês, cobre e boro foram, respectivamente, 9,$5 ; 108,6$; 120,$5 ; 3,1$ e $0,70 \mathrm{mg} / \mathrm{dm}^{3}$. A análise granulométrica indicou $26 \%$ de argila, $12 \%$ de silte, $40 \%$ de areia grossa e $22 \%$ de areia fina, classificação textural francoargilo-arenosa. Com base na análise do solo foram feitos os cálculos da correção de acidez e adubação, segundo as
"Recomendações para o Uso de Corretivos e Fertilizantes em Minas Gerais (5 aproximação)". Em setembro de 2005, foram aplicados 1,6t/ha de calcário dolomítico $(23 \%$ de $\mathrm{CaO}, 15 \%$ $\mathrm{MgO}$ e PRNT de 53,28\%), seguida de aração e duas gradagens, no mesmo período Em 09/02/06, foi feita aplicação de herbicida, a base de glifosate, para eliminar as plantas invasoras, uma vez que não se promoveu nenhuma intervenção mecânica no solo, após o preparo feito em setembro de 2005.

O delineamento experimental foi em blocos completos casualizados com três repetições e os tratamentos foram arranjados em fatorial $3 \times 5$, constituído pelas cultivares de milheto Comum, BN2 e BRS1501, plantadas em meados dos meses de fevereiro, março, abril, agosto e setembro. 
Em 22/02/06, foi realizada a semeadura da $1^{\text {a }}$ época, utilizando $20 \mathrm{~kg} / \mathrm{ha}$ de sementes. Como as sementes foram obtidas por doação de empresas comerciais, em embalagens não utilizadas no comércio convencional, não continham informações de pureza e germinação. A partir de um teste de germinação, realizado, após o primeiro plantio, obteve-se germinação média de $60 \%$, o que levou a decisão de elevar a densidade de semeadura para $30 \mathrm{~kg} / \mathrm{ha}$ nos plantio seguintes, mantendo-se o espaçamento de $50 \mathrm{~cm}$ entre linhas. No plantio de março, houve comprometimento do estande devido ao ataque de insetos às plântulas recémemergidas. $\mathrm{O}$ inseto não foi identificado, inicialmente, e, a partir de sua detecção, foi feito o controle com o uso de inseticida a base de deltametrina.

Com base nas "Recomendações para o Uso de Corretivos e Fertilizantes em Minas Gerais ( $5^{\mathrm{a}}$ aproximação)" foram aplicados $350 \mathrm{~kg} / \mathrm{ha}$ da fórmula $08-28$ 16 nos sulcos de plantio. O adubo foi homogeneizado com o solo antes da colocação das sementes. Após cada corte, a adubação em cobertura foi realizada com aplicação de $200 \mathrm{~kg} / \mathrm{ha}$ da fórmula 20-00-20. A área de cada unidade experimental foi de $10 \mathrm{~m}^{2}(2,5 \mathrm{x}$ $4 \mathrm{~m})$ e os tratamentos não receberam irrigação.

Em 20/11/06, ocorreu a entrada incidental de animais no experimento. Todas as parcelas do plantio de setembro, que já estavam próximas da segunda colheita, foram pastejadas, consequentemente, ficou um resíduo em torno de 20 a $30 \mathrm{~cm}$ de altura. Como a colheita era feita a $10 \mathrm{~cm}$ de altura, optou-se por uma roçada de uniformização de todas as parcelas a essa altura, em 22/11/06, para iniciar novo crescimento e continuar as avaliações. Para o número de dias de rebrota, utilizado no cálculo da produtividade diária, considerou-se a data inicial correspondendo ao corte de uniformização. $O$ período entre a colheita anterior e o pastejo não foi contabilizado. As colheitas foram feitas ao início do amarelecimento das folhas baixeiras ou quando emitiam inflorescência. Para a colheita, foi tirada a bordadura, que compreendia as duas fileiras laterais da parcela e $0,5 \mathrm{~m}$ das extremidades das três fileiras restantes. Antes da colheita da área útil, foi tomada a medida de altura do dossel, fazendo-se três medidas em pontos diferentes da parcela. A massa de forragem colhida foi pesada, amostrada e separada em lâmina foliar+panícula e colmo+bainha e postas a secar em estufa com ventilação forçada a $65^{\circ} \mathrm{C}$ por 72 horas. A massa de forragem seca média refere-se à massa de forragem seca total, dividida pelo número de cortes em cada cultivar ou época. Para o cálculo da produtividade diária, a produção obtida em cada corte foi dividida pelo tempo, em dias, entre a semeadura e a $1^{\text {a }}$ colheita ou entre dois cortes. Após secagem, as amostras foram moídas em moinho tipo Willey, em peneira com $1 \mathrm{~mm}$ de abertura e acondicionadas em frascos para análises dos teores de matéria seca. Somente as amostras de lâmina foliar foram analisadas quanto aos teores de proteína bruta (PB), fibra em detergente neutro (FDN) e digestibilidade in vitro da matéria seca (DIVMS), conforme Silva \& Queiroz (2002). As médias dos teores de PB, FDN e DIVMS em cada cultivar ou colheita, foram calculadas pela média ponderada dos teores desses fatores em cada colheita ou cultivar pela produção de massa seca de lâmina foliar correspondente. $\mathrm{Na}$ Tabela 1, são apresentadas as datas dos plantios e colheitas, bem como os intervalos entre a semeadura e a $1^{\text {a }}$ colheita $e$ as colheitas seguintes. 
Rev. Bras. Saúde Prod. Anim., Salvador, v.13, n.2, p.318-329 abr./jun., 2012 http://www.rbspa.ufba.br ISSN 15199940

Tabela 1. Data de semeadura e de colheitas, intervalo entre a semeadura e a $1^{\text {a }}$ colheita e as colheitas seguintes das cultivares de milheto

\begin{tabular}{|c|c|c|c|c|}
\hline \multirow{2}{*}{ Época/Cultivar } & \multirow{2}{*}{$\begin{array}{c}\text { Data de } \\
\text { semeadura }\end{array}$} & \multicolumn{3}{|c|}{ Colheitas } \\
\hline & & $1^{\mathrm{a}}$ & $2^{a}$ & $3^{a}$ \\
\hline $1 \mathrm{BN} 2$ & $22 / 02$ & $04 / 04(41)^{T}$ & $27 / 04(23)$ & $26 / 05(29)$ \\
\hline 1 COMUM & $22 / 02$ & $04 / 04(41)$ & 27/04 (23) & $26 / 05$ (29) \\
\hline 1 BRS1501 & $22 / 02$ & $04 / 04(41)$ & $27 / 04(23)$ & $26 / 05(29)$ \\
\hline $2 \mathrm{BN} 2$ & $17 / 03$ & $20 / 04(34)$ & $26 / 05(36)$ & $\mathrm{N}$ \\
\hline 2 COMUM & $17 / 03$ & 20/04 (34) & $26 / 05(36)$ & $\mathrm{N}$ \\
\hline 2 BRS1501 & $17 / 03$ & 20/04 (34) & $26 / 05(36)$ & $\mathrm{N}$ \\
\hline $3 \mathrm{BN} 2$ & $11 / 04$ & $23 / 05(42)$ & $18 / 07(56)$ & $\mathrm{N}$ \\
\hline 3 COMUM & $11 / 04$ & 23/05 (42) & 18/07 (56) & $\mathrm{N}$ \\
\hline 3 BRS1501 & $11 / 04$ & $23 / 05(42)$ & $18 / 07(56)$ & $\mathrm{N}$ \\
\hline $4 \mathrm{BN} 2$ & $16 / 08$ & $11 / 10(56)$ & $08 / 11(28)$ & $\mathrm{N}$ \\
\hline 4 COMUM & $16 / 08$ & $11 / 10(56)$ & 08/11 (28) & $\mathrm{N}$ \\
\hline 4 BRS1501 & $16 / 08$ & $11 / 10(56)$ & 08/11 (28) & $\mathrm{N}$ \\
\hline $5 \mathrm{BN} 2$ & $14 / 09$ & $26 / 10(42)$ & $21 / 12^{*}(29)$ & $\mathrm{N}$ \\
\hline 5 COMUM & $14 / 09$ & $26 / 10(42)$ & $19 / 12^{*}(27)$ & $\mathrm{N}$ \\
\hline 5 BRS1501 & $14 / 09$ & $26 / 10(42)$ & $21 / 12^{*}(29)$ & $\mathrm{N}$ \\
\hline
\end{tabular}

$\mathrm{N}$ - não houve colheita.

*Colheita após pastejo incidental em 20/11 (corte de uniformização em 22/11).

${ }^{1}$ Valores entre parênteses referem-se ao intervalo em dias.

Os dados foram avaliados por meio de análise de variância e teste de média, utilizando-se o Sistema de Análises Estatísticas e Genéticas - SAEG (UFV, 2001). Para a comparação das médias, foi empregado o teste Student-NewmanKeuls (SNK), a 5\% de probabilidade.

\section{RESULTADOS E DISCUSSÃO}

$\mathrm{O}$ milheto propiciou pequeno número de colheitas, com o máximo de três no plantio em fevereiro e duas nas demais épocas de plantio para todas as cultivares testadas. O plantio na interface chuva/seca coincide com a redução no comprimento do dia e induz o florescimento do milheto, mesmo em condições de baixo acúmulo de forragem. O milheto sofre efeito de fotoperíodo, o que pode encurtar o seu ciclo de crescimento no outono (SKERMAN \& RIVEROS, 1990).

Apesar da boa tolerância a estresses hídricos, o que permite seu cultivo em épocas de menor precipitação (GUIMARÃES JÚNIOR et al, 2009), os baixos volumes acumulados nos meses de junho, julho e agosto (Figura 1) foram insuficientes para a rebrota das plantas, ocasionando a sua morte.

$\mathrm{O}$ intervalo entre a semeadura e a primeira colheita ficou em torno dos 40 dias, exceto no plantio de agosto (Tabela 1), quando a precipitação pluviométrica foi muito baixa, 
retardando o crescimento das plantas (Figura 1). O intervalo entre as rebrotas ficou dependente da precipitação pluviométrica e foi mais longo (56 dias) na $2^{\mathrm{a}}$ colheita do plantio de abril que ocorreu no mês de julho. Os demais intervalos ficaram entre 25 e 30 dias e ocorreram em períodos com alguma precipitação pluviométrica. Apesar de sofrer efeito do fotoperíodo na semeadura da interface chuva/seca e da baixa capacidade de rebrotação com $o$ avanço das colheitas, o milheto pode ser uma alternativa interessante para a produção de forragem na safrinha, após a colheita da cultura de verão, em função de seu rápido crescimento, que permite a colheita ou pastejo em aproximadamente 40 dias, após a semeadura.

Costa et al. (2005) estudaram cultivares de milheto, entre as quais a cv. BRS1501, semeadas em janeiro e março. Em março, as plantas atingiram condições de colheita para produção de forragem entre 27 e 40 dias após a semeadura, a coincidir com as fases E3 (inicio da formação da panícula) e E4 (emissão da folha bandeira). Critério de corte semelhante ao desses autores foi usado nesse trabalho, já que o amarelecimento das folhas baixeiras coincidia, aproximadamente, ao inicio de formação da panícula. Em trabalhos sob pastejo, Pedroso et al. (2009) e Restle et al. (2002) submeteram o milheto ao primeiro pastejo aos 45 e 41 dias após a semeadura, respectivamente. A análise de variância não apresentou efeito $(\mathrm{P}>0,05)$ da interação cultivar $\mathrm{x}$ época de plantio para as variáveis de produção massa de forragem seca total (MSFT), massa de lâmina foliar seca total (MSLT), massa de forragem seca média (MSFmédia) e produtividade diária (PRODIA); para as variáveis estruturais relação $\mathrm{F} / \mathrm{C}$ e altura média e para o teor de PB. Houve efeito de época para todas as variáveis dependentes avaliadas, cujos valores de $\mathrm{F}$ foram altos, conforme se observa pelos níveis de significância alcançados na análise de variância (Tabela 2). Houve efeito de cultivar somente para os teores de PB e DIVMS, mas os valores de $\mathrm{F}$ foram baixos, o que indica efeito menos intenso que a época.

Tabela 2. Quadro da análise de variância com valores de $\mathrm{F}$ realçando os níveis de significância e o coeficiente de variação

\begin{tabular}{lcccc}
\hline Variáveis & Época & Cultivar (cult) & Interação & Coeficiente de \\
\hline MSFT & $19,75^{* * *}$ & $3,13^{\mathrm{ns}}$ & $0,61^{\mathrm{ns}}$ & 22,06 \\
MSLT & $25,22^{* * *}$ & $2,48^{\mathrm{ns}}$ & $0,90^{\mathrm{ns}}$ & 20,59 \\
MSFmédia & $27,93^{* * *}$ & $2,93^{\mathrm{ns}}$ & $0,61^{\mathrm{ns}}$ & 22,00 \\
Relação F/C & $5,39^{* *}$ & $0,69^{\mathrm{ns}}$ & $1,00^{\mathrm{ns}}$ & 15,11 \\
Altura média & $20,66^{* * *}$ & $1,42^{\mathrm{ns}}$ & $1,92^{\mathrm{ns}}$ & 7,25 \\
PRODIA & $30,31^{* * *}$ & $2,59^{\mathrm{ns}}$ & $0,58^{\mathrm{ns}}$ & 22,73 \\
Proteína bruta & $28,89^{* * *}$ & $7,91^{* * *}$ & $1,53^{\mathrm{ns}}$ & 5,14 \\
FDN & $49,91^{* * *}$ & $1,23^{\mathrm{ns}}$ & $7,20^{* * *}$ & 1,99 \\
DIVMS & $57,86^{* * *}$ & $19,90^{* * *}$ & $9,51^{* * *}$ & 1,75 \\
\hline
\end{tabular}

${ }^{* * *},{ }^{* *},{ }^{*}$ significativo ao nível de 0,$1 ; 1$ e $5 \%$, respectivamente. ${ }^{\text {ns }}$ não significativo. Massa de forragem seca total (MSFT), massa de lâmina foliar seca total (MSLT), massa de forragem seca média (MSF média), Relação folha colmo (Relação $\mathrm{F} / \mathrm{C}$ ), produtividade diária (PRODIA), fibra em detergente neutro (FDN) e digestibilidade in vitro da matéria seca (DIVMS). 
A ausência de interação significativa entre épocas de plantio e cultivares para a maioria das variáveis aponta que o desempenho das cultivares é semelhante, independente da época de plantio

Não houve efeito de cultivares sobre as variáveis de produção, conforme se visualiza pela ausência de diferença quanto a produção de MSFT, MSF média e produtividade diária (Tabela 3). Kollet et al. (2006) verificaram que a produção de matéria seca não diferiu entre os genótipos de milheto Africano, Americano e BN2 plantados em março, cuja produção aos 42 dias foi de 3.918, 3.013 e $2.669 \mathrm{~kg} / \mathrm{ha}$, respectivamente. Também observaram baixo vigor de rebrota dessas variedades, 410; 224 e
$564 \mathrm{~kg} / \mathrm{ha}$, cuja produção total alcançou 4.328; 3.237 e $3.233 \mathrm{~kg} / \mathrm{ha}$, respectivamente, semelhantes às obtidas nesse trabalho. Pires et al. (2007) estudaram as cultivares ADR500, ADR300 e BN2 colhidas em vários estádios de desenvolvimento.

No estádio de pré-florescimento, aos 45 dias após a semeadura, obteve produções de 6,$31 ; 5,01$ e 4,21t/ha, respectivamente, caracterizando superioridade das cultivares ADR's em relação a BN2, cuja produção foi equivalente às obtidas nesse experimento. Deve-se ressaltar que o experimento de Pires et al. (2007) foi conduzido no período de primavera/verão, quando as respostas de produção do milheto são melhores.

Tabela 3. Médias das variáveis de produção e de composição química por cultivar nas épocas de plantio de fevereiro a setembro

\begin{tabular}{lcccc}
\hline \multirow{2}{*}{ Variáveis } & \multicolumn{3}{c}{ Cultivares } & \multirow{2}{*}{ Média } \\
\cline { 2 - 4 } & BN2 & Comum & BRS1501 & \\
\hline MSFT (kg/ha) & $4.277^{\mathrm{a}}$ & $4.208^{\mathrm{a}}$ & $3.545^{\mathrm{a}}$ & 4.010 \\
MSLT (kg/ha) & $2.265^{\mathrm{a}}$ & $2.300^{\mathrm{a}}$ & $1.969^{\mathrm{a}}$ & 2.178 \\
MSFmédia (kg/ha) & $1.986^{\mathrm{a}}$ & $1.972^{\mathrm{a}}$ & $1.663^{\mathrm{a}}$ & 1.874 \\
PRODIA (kg/ha) & $51,59^{\mathrm{a}}$ & $53,15^{\mathrm{a}}$ & $44,35^{\mathrm{a}}$ & 49,70 \\
PB (\%) & $15,47^{\mathrm{b}}$ & $16,32^{\mathrm{a}}$ & $16,64^{\mathrm{a}}$ & 16,14 \\
FDN (\%) & $53,13^{\mathrm{a}}$ & $53,50^{\mathrm{a}}$ & $53,73^{\mathrm{a}}$ & 53,45 \\
\hline
\end{tabular}

Diferentes letras minúsculas na linha indicam diferença estatística pelo teste $\mathrm{SNK}(\mathrm{P}<0,05)$. Massa de forragem seca total (MSFT), massa de lâmina foliar seca total (MSLT), massa de forragem seca média (MSF média), produtividade diária (PRODIA), proteína bruta (PB) e fibra em detergente neutro (FDN).

Os teores de $\mathrm{PB}$ foram relativamente altos em todas as cultivares, ao observado na maioria das forrageiras tropicais, variando de 15,47 a $16,64 \%$. A cultivar BN2 apresentou menor teor de PB que as demais cultivares. Não se distinguiu nenhum fator que pudesse justificar as diferenças encontradas, a exceção da menor produção de lâminas foliares na cultivar 1501 que poderia ter algum efeito de concentração de nitrogênio. Os valores obtidos nesse trabalho estão em sintonia com os de Kollet et al. (2006), que obtiveram 15,42 e 55,78\% para os teores de PB e FDN em três cultivares de milheto, colhidos aos 42 dias de idade. As cultivares de milheto apresentaram composição química e DIVMS bem elevados relativamente do que a maioria dos volumosos oriundos de gramíneas forrageiras tropicais.

As diferenças entre as épocas de plantio foram bem nítidas (Tabela 4). Todas as variáveis de produção apresentaram 
melhor desempenho no plantio em setembro. $O$ plantio, na interface chuva/seca, além de estar sujeito à redução na precipitação, recebe o estímulo ao florescimento, decorrente do encurtamento no comprimento do dia. Não houve diferença entre os meses de fevereiro e abril para a maioria das variáveis de produção, à exceção da massa de forragem seca média. Apesar de ainda apresentar condições ambientais razoáveis, com boa precipitação (Figura 1), o plantio em março ficou prejudicado por ataque de insetos às plântulas recémemergidas, o que conduziu a estande abaixo do projetado. Especula-se que o perfilhamento do milheto poderia compensar parcialmente a menor densidade inicial de plantas, mas não foi de magnitude suficiente para equiparar as produções do plantio em março às demais épocas. Negreiros et al. (2010) e Priesnitz et al. (2011) avaliaram espaçamentos de plantio de milheto e verificaram que a produção de biomassa reduz à medida que se aumenta o espaçamento de plantio, a indicar que de fato a compensação na população de perfilhos ou na relação tamanho/densidade de perfilhos não foi suficiente para equiparar as produções com a ampliação no espaçamento de plantio.

Tabela 4. Média das variáveis de produção e de composição química das cultivares de acordo com as épocas de semeadura

\begin{tabular}{lccccc}
\hline \multirow{2}{*}{ Variável } & \multicolumn{5}{c}{ Épocas de plantio } \\
\cline { 2 - 6 } & Fevereiro & Março & Abril & Agosto & Setembro \\
\hline MSFT (kg/ha) & $3.941^{\mathrm{bc}}$ & $2.525^{\mathrm{d}}$ & $4.316^{\mathrm{b}}$ & $3.258^{\mathrm{cd}}$ & $6.010^{\mathrm{a}}$ \\
MSLFT (kg/ha) & $1.974^{\mathrm{b}}$ & $1.312^{\mathrm{c}}$ & $2.339^{\mathrm{b}}$ & $1.917^{\mathrm{b}}$ & $3.347^{\mathrm{a}}$ \\
MSF média (kg/ha) & $1.314^{\mathrm{c}}$ & $1.263^{\mathrm{c}}$ & $2.158^{\mathrm{b}}$ & $1.629^{\mathrm{c}}$ & $3.005^{\mathrm{a}}$ \\
PRODIA (kg/ha) & $37,31^{\mathrm{b}}$ & $35,70^{\mathrm{b}}$ & $46,18^{\mathrm{b}}$ & $43,32^{\mathrm{b}}$ & $85,97^{\mathrm{a}}$ \\
Altura (cm) & $93^{\mathrm{b}}$ & $101^{\mathrm{a}}$ & $78^{\mathrm{c}}$ & $100^{\mathrm{a}}$ & $103^{\mathrm{a}}$ \\
Relação F/C & $1,60^{\mathrm{a}}$ & $1,25^{\mathrm{b}}$ & $1,26^{\mathrm{b}}$ & $1,50^{\mathrm{a}}$ & $1,27^{\mathrm{b}}$ \\
PB (\%) & $15,40^{\mathrm{c}}$ & $17,95^{\mathrm{a}}$ & $14,04^{\mathrm{d}}$ & $16,73^{\mathrm{b}}$ & $16,60^{\mathrm{b}}$ \\
\hline
\end{tabular}

Diferentes letras minúsculas na linha indicam diferença estatística pelo teste SNK $(\mathrm{P}<0,05)$. Massa de forragem seca total (MSFT), massa de lâmina foliar seca total (MSLT), massa de forragem seca média (MSF média), produtividade diária (PRODIA), proteína bruta (PB) e fibra em detergente neutro (FDN).

Três fatores apresentam alta correlação negativa com a relação lâmina foliar/colmo: a produção de matéria seca, a altura do dossel e a emissão de inflorescência. A forragem colhida nos meses de março e abril apresentaram mais baixa relação lâmina foliar/colmo que as épocas de fevereiro e agosto, provavelmente decorrente de maior florescimento estimulado por dias curtos. Apesar do maior teor de PB da forragem produzida em março, provavelmente decorrente da mais baixa produtividade, em todas as épocas de plantio, a qualidade da forragem foi alta.

Em abril, a altura do dossel foi mais baixa, seguida do mês de fevereiro, sem haver diferença entre as demais épocas de plantio. O milheto apresenta uma característica de crescimento em que os perfilhos são emitidos continuamente. Assim, no momento da colheita são encontrados perfilhos na fase reprodutiva e em diversos estádios da fase vegetativa. Isso faz com que a altura e até mesmo 
a relação lâmina foliar/colmo sejam medidas pouco reveladoras da condição do dossel e fiquem sujeitas a maior risco de erro no momento da amostragem e alto coeficiente de variação.

Uemura et al. (1997) testaram diferentes épocas de semeadura de milheto na entressafra, sob condições de irrigação, e obtiveram menores produções com o plantio em março ou abril, em relação ao de agosto, tal efeito é atribuído à redução no fotoperíodo. Nas condições ambientais de Leopoldina, é provável que a baixa precipitação e a redução no fotoperíodo sejam as causas mais importantes na determinação do potencial de produção do milheto, considerando que a altitude em torno de $200 \mathrm{~m}$ condiciona invernos pouco rigorosos e baixa restrição térmica, mesmo para o cultivo de forrageiras tropicais. Obviamente que a questão da época de plantio deve ser vista com reserva, a depender da região e das variações entre anos.

Nesse experimento, a precipitação acumulada entre o plantio de agosto e a primeira colheita totalizou $120 \mathrm{~mm}$ em 56 dias. Já no plantio de setembro, a precipitação foi de $233 \mathrm{~mm}$, entre a semeadura e a primeira colheita, feita 42 dias depois. Certamente, o plantio de setembro foi beneficiado pela precipitação acima da média no mês de outubro (Figura1), cuja colheita ocorreu no fim deste. O levantamento da precipitação histórica na região do produtor que quiser usar o milheto, para cultivo nas transições chuva/seca e seca/chuva, é o primeiro passo para tomar a decisão da época de menor risco para o plantio do milheto.

Parece claro que o plantio do milheto, na primavera, produz as melhores respostas em produção, e essa informação encontra amparo na literatura (UEMURA et al., 1997; COSTA et al., 2005; COIMBRA \& NAKAGAWA, 2006). Apesar das condições mais favoráveis, somente dois cortes foram realizados nos plantios de agosto e setembro, o que indicou pobre rebrotação do milheto, a partir do terceiro corte. Ainda assim, os valores de produtividade diária, obtidos em setembro foram muito superiores às demais épocas de plantio, o que reforça a indicação dessa época de plantio. Embora esse trabalho e o de Kollet et al. (2006) realçem a baixa capacidade de rebrotação do milheto cultivado na interface chuva/seca, Farinelli et al. (2004) semearam a cultivar BN2 nos meses de abril, maio e junho na região de Botucatu-SP e obtiveram excelente condição de rebrota com até cinco cortes, ao início de florescimento no plantio em abril, com produção média por corte nas três épocas de $4.656 \mathrm{~kg} / \mathrm{ha}$.

Houve interação $(\mathrm{P}<0,05)$ entre cultivares e épocas para os teores de FDN e DIVMS (Tabela 5). Os teores de FDN variaram de 48,78 a $57,27 \%$ (Tabela 5). A forragem produzida nos plantios de fevereiro, abril e agosto apresentou mais altos teores de FDN em relação àquela produzida em março e setembro, mas não se pode estabelecer ligação com a produção de forragem, uma vez que nesses meses de plantio, produções intermediárias foram obtidas. Há forte correlação entre os teores de FDN e o grau de maturidade das gramíneas forrageiras (VAN SOEST, 1994).

No caso desse experimento, o critério de colheita ao aparecimento de amarelecimento das folhas baixeiras proporcionou maturidade fisiológica semelhante entre as plantas colhidas nas diferentes épocas, o que torna pouco provável essa possibilidade. Outro fator que influencia os teores de FDN é a temperatura ambiental. A alta temperatura promove conversão mais rápida dos metabólitos, em componentes estruturais (VAN SOEST, 1994). Nesse caso a adequação entre os meses de plantio com mais alto teor de FDN (fevereiro, 
abril e agosto) também não está ajustado com as variações da temperatura que normalmente são mais amenas no outono/inverno. Menores valores de DIVMS ocorreram no plantio de agosto e os maiores em fevereiro e março. De modo geral, a qualidade da forragem foi alta $\mathrm{e}$ as variações encontradas não contêm elementos de associação claros com aspectos de produção e de condição ambiental.

Tabela 5. Teores de fibra em detergente neutro e digestibilidade in vitro da matéria seca de três cultivares de milheto em cinco épocas de plantio

\begin{tabular}{lccccc}
\hline \multirow{2}{*}{ Cultivar } & \multicolumn{5}{c}{ Épocas de plantio } \\
\cline { 2 - 5 } & Fevereiro & Março & Abril & Agosto & Setembro \\
\hline BN2 & $55,61^{\mathrm{Aa}}$ & $51,32^{\mathrm{Ab}}$ & $53,59^{\mathrm{Ba}}$ & $54,18^{\mathrm{Ba}}$ & $50,94^{\mathrm{Bb}}$ \\
Comum & $53,64^{\mathrm{Bb}}$ & $48,78^{\mathrm{Bc}}$ & $56,28^{\mathrm{Aa}}$ & $56,61^{\mathrm{Aa}}$ & $52,17^{\mathrm{Bb}}$ \\
BRS1501 & $52,97^{\mathrm{Bc}}$ & $48,86^{\mathrm{Bd}}$ & $55,29^{\mathrm{ABb}}$ & $57,27^{\mathrm{Aa}}$ & $54,25^{\mathrm{Abc}}$ \\
\hline \multicolumn{5}{c}{ Digestibilidade in vitro } \\
\hline BN2 & $72,31^{\mathrm{Aa}}$ & $72,21^{\mathrm{Aa}}$ & $68,52^{\mathrm{Ab}}$ & $61,37^{\mathrm{Cd}}$ & $63,61^{\mathrm{Bc}}$ \\
Comum & $71,02^{\mathrm{Aab}}$ & $72,06^{\mathrm{Aa}}$ & $69,18^{\mathrm{Ab}}$ & $69,24^{\mathrm{Ab}}$ & $70,16^{\mathrm{Ab}}$ \\
BRS1501 & $72,15^{\mathrm{Aa}}$ & $72,68^{\mathrm{Aa}}$ & $69,86^{\mathrm{Ab}}$ & $64,32^{\mathrm{Bc}}$ & $68,40^{\mathrm{Ab}}$ \\
\hline Diferentes letras maiúsculas nas colunas e minúsculas nas linhas indicam diferença estatística a 5\% de \\
significância pelo teste SNK.
\end{tabular}

Maiores teores de FDN e menores de digestibilidade foram obtidos no milheto semeado em agosto nas cultivares BRS1501 e BN2, respectivamente. O maior intervalo entre a semeadura e a primeira colheita (56 dias) ocorreu nessa época de plantio (Tabela 1). Como os valores médios de FDN e DIVMS entre as colheitas foram obtidos por meio da média ponderada, a utilizar a massa de lâmina foliar seca, a contribuição da primeira colheita foi bem maior que da segunda, o que afetou negativamente $o$ valor decorrente do mais longo período de crescimento. Sabe-se que o estádio de maturidade é um dos principais fatores na redução do valor nutritivo de forrageiras tropicais. Apesar das variações no teor de FDN, a cultivar comum manteve alta digestibilidade em todas as épocas de plantio.

O plantio, em fevereiro, foi o único que permitiu três colheitas, com excelente produção na primeira colheita, mas a produção da segunda e terceira colheitas foi muito baixa para todas as cultivares, o que resultou uma baixa produtividade diária média por corte. Provavelmente, o fato do milheto não ter sido desenvolvido para uso forrageiro conduza a baixa capacidade de rebrotação e o limitado número de cortes realizados em todas as variedades e épocas. Isso significa que o milheto para produção de forragem deve estar inserido numa proposta de uso por curto período, a ocupar intervalos entre dois cultivos, ou usado, estrategicamente, para aliviar a pressão de pastejo em áreas de pastagem ou complementar a suplementação volumosa em determinados períodos do ano.

Dentro dessa proposta, o milheto pode atender com eficiência um sistema de integração lavoura-pecuária. Plantado na safrinha, entre fevereiro e abril, permite que sejam feitos alguns pastejos, durante 
o período de entressafra, finalizando com o diferimento no início da estação chuvosa para acumular palha para o plantio direto da lavoura. O plantio, em setembro, apesar de permitir melhores produtividades, pode impedir ou retardar a implantação das culturas de verão, a dificultar sua inserção no sistema de produção de grãos e forragem.

As diferenças encontradas entre as cultivares foram de pequena magnitude e variáveis com as épocas de plantio, o que indica que entre as cultivares estudadas não há uma que reúna todas as características desejáveis para recomendá-la isoladamente, isto é, qualquer uma das cultivares estudadas pode ser utilizada. Os efeitos de época são muito mais determinantes do desempenho. A semeadura, em setembro, propiciou os melhores resultados sobre a produção (MSFT, MSLT, MSFmédia e PRODIA), com a PRODIA alcançando o dobro das outras épocas.

A semeadura na interface chuva/seca deve ser recomendada com reserva para o milheto, que apresenta sensibilidade ao fotoperíodo, a comprometer a rebrotação e a produção de forragem. Integrada em um sistema de produção de forragem, ao longo do ano, para atender às necessidades do rebanho, passa a ser uma alternativa interessante, apesar do menor potencial de produção. A semeadura, em agosto, implica maior risco pela baixa precipitação pluviométrica, enquanto a semeadura, em setembro, proporcionou as melhores respostas em produtividade de matéria seca.

\section{AGRADECIMENTOS}

Os autores agradecem ao Técnico Agrícola Sérgio Dutra de Resende pelo auxilio nas atividades em campo.

\section{REFERÊNCIAS}

ANTUNES, F.Z. Caracterização climática do Estado de Minas Gerais. Informe Agropecuário, v.12, n.138, p.913, 1986.

COIMBRA, R.A.; NAKAGAWA, J. Época de semeadura e regimes de corte na produção de fitomassa e grãos de milheto forrageiro. Revista Brasileira de Milho e Sorgo, v.5, n.1, p.89-100, 2006.

COSTA, A.C.T.; GERALDO, J.; PEREIRA, M.B.; PIMENTEL, C. Unidades térmicas e produtividade em genótipos de milheto semeados em duas épocas. Pesquisa Agropecuária

Brasileira, v.40, n.12, p.1171-1177, 2005

COSTA, V.G.; ROCHA, M.G.; PÖTTER, L.; ROSO, D.; ROSA, A.T.N.; REIS, J. Comportamento de pastejo e ingestão de forragem por novilhas de corte em pastagens de milheto e papua.

Revista Brasileira de Zootecnia, v.40, n.2, p.251-259, 2011.

EMBRAPA. Sistema de classificação brasileiro de classificação de solos. 2.ed. Rio de Janeiro: EMBRAPA/Centro Nacional de Pesquisa de Solos, 2006. $306 p$.

FARINELLI, R.; LEMOS, L.B.; PENARIOL, F.G.; NASCIMENTO, E.S. Desempenho da cultura do milheto em função de épocas de semeadura e do manejo de corte da parte aérea. Revista Brasileira de Milho e Sorgo, v.3, n.3, p.391-401, 2004.

GUIMARÃES JÚNIOR, R.; GONÇALVES, L.C.; RODRIGUES, J.A.S. Utilização do milheto para produção de silagem. Planaltina, DF: Embrapa Cerrados, 2009.

30p.(Documentos, 259). 
Rev. Bras. Saúde Prod. Anim., Salvador, v.13, n.2, p.318-329 abr./jun., 2012 http://www.rbspa.ufba.br ISSN 15199940

KOLLET, J.L.; DIOGO, J.M.S.;

LEITE, G.G. Rendimento forrageiro e composição bromatológica de variedades de milheto (Pennisetum glaucum (L.) R. BR.). Revista

Brasileira de Zootecnia, v.35, n.4, p.1308-1315, 2006.

NEGREIROS NETO, J.V.; SANTOS, A.C.; LEITE, R.L.L.; CRUZ, R.S. Análise de diferentes doses de nitrogênio e espaçamento em milheto no norte do Tocantins. Revista

Biotemas, v.23, n.4, p.19-23, 2010.

PEDROSO, C.E.S.; MONKS, P.L.; FERREIRA, O.G.L.; LIMA, L.S.; TAVARES, O.M. Características morfogênicas de milheto sob lotação rotacionada com diferentes períodos de descanso. Revista Brasileira de Zootecnia, v.38, n.12, p.2311-2319, 2009.

PIRES, F.R.; ASSIS, R.L.; SILVA, G.P.; BRAZ, A.J.B.P.; SANTOS, S.C.; VIEIRA NETO, S.A.; SOUSA, J.P.G. Desempenho agronômico de variedades de milheto em razão da fenologia em pré-safra. Bioscience Journal, v.23, n.3, p.41-49, 2007.

PRIESNITZ, R.; COSTA, A.C.T.; JANDREY, P.E.; FRÉZ, J.R.S.; DUARTE JÚNIOR, J.B.; OLIVEIRA, P.S.R. Espaçamento entre linhas na produtividade de biomassa e de grãos em genótipos de milheto pérola.

Semina: Ciências Agrárias, v.32, n.2, p.485-494, 2011.
RESTLE, J.; ROSO, C.; AITA, V.; NÖRNBERG, J.L.; BRONDANI, I.L.; CERDÓTES, L.; CARRILHO, C.O. Produção animal em pastagem com gramíneas de estação quente. Revista Brasileira de Zootecnia, v.31, n.3, p.1491-1500, 2002 (suplemento).

SKERMAN, P.J.; RIVEROS, F. Tropical grasses. Rome: FAO, 1990. 823p.

SILVA, D.J.; QUEIROZ, C. Análise de alimentos: métodos químicos $\mathrm{e}$ biológicos. Viçosa, MG: Universidade Federal de Viçosa, 2002. 235p.

SPEHAR, C.R.; TRECENTI, R. Desempenho agronômico de espécies tradicionais e inovadoras da agricultura em semeadura de sucessão e entressafra no cerrado do planalto central brasileiro. Bioscience Journal, v.27, n.1, p.102-111, 2011. UEMURA, Y.; URBEN FILHO, G.; NETTO, D.A.M. Pearl millet as a cover crop for no-till soybean production in Brazil. In: International Sorghum and Millets Newsletter, n.38, p. 141-143, 1997.

UNIVERSIDADE FEDERAL DE VIÇOSA - UFV. Sistema para análise estatística e genética- SAEG. Versão 8.0. Viçosa, MG: Fundação Arthur Bernardes, 2001. 150p.

VAN SOEST, P.J. Nutritional ecology of the ruminant. $2^{\text {nd }}$ ed. New York: Cornell University, 1994. 476p.

Data de recebimento: 30/09/2011

Data de aprovação: 19/04/2012 